\title{
ESTUDO PARA REDUÇÃO DE CUSTOS E OTIMIZAÇÃO DO PROCESSO DE PINTURA DE COMPONENTES INDUSTRIAIS DA EMPRESA "CEI"
}

\section{STUDY FOR COST REDUCTION AND OPTIMIZATION OF THE PAINT PROCESS OF INDUSTRIAL COMPONENTS OF THE "CEI" COMPANY}

\author{
Péricles Bosquetti ${ }^{\mathrm{I}}$ \\ Narieli Soares da Silva II \\ Elaine Almeida Badaró ${ }^{I I I}$ \\ Antônio Carlos Ventura Junior ${ }^{\mathrm{IV}}$ \\ Diógenes Bosquetti ${ }^{\mathrm{V}}$
}

\begin{abstract}
RESUMO
Considerando-se a atual crise do Brasil e o mercado altamente competitivo, torna-se fundamental reduzir os custos de um processo produtivo. Neste trabalho o objetivo foi de apresentar uma solução para redução de altos custos na realização de jateamento e pintura industrial focando as necessidades de uma empresa, denominada "CEI". Para isso, buscou-se analisar vários pontos relacionado aos custos de um processo de pintura, desde o levantamento de orçamento dos equipamentos necessários até a realização da pintura nas peças, a fim de localizar o que ocasiona os elevando os custos. Como resultados, fez-se uma proposta da aquisição de uma cabine de jateamento e pintura dentro da própria empresa. Para esta proposta, foram necessários levantar os custos para implantação da mesma, apresentar simulações de como a implantação da cabine poderia trazer lucros e em quanto tempo seria possível a recuperação dos investimentos, explanando as economias geradas.
\end{abstract}

Palavras-chave: Custos. Redução. Jateamento. Pinturas Industriais.

\begin{abstract}
Considering the current Brazilian crisis and the highly competitive market, it is essential to reduce the costs of a productive process. In this work the objective was to present a solution to reduce high costs in the accomplishment of blasting and industrial painting focusing on the needs of a company, called "CEI". In order to do this, we sought to analyze several points related to the costs of a painting process, from the budgeting of the necessary equipment to the painting in the pieces, in order to locate what causes the raising costs. As a result, a proposal was made to acquire a paint and blast booth inside the company. For this proposal, it was necessary to raise the costs to implement the same, to present simulations of how the

\footnotetext{
I Prof. Dr. da Faculdade de Tecnologia (FATEC) de Sertãozinho - São Paulo - Brasil. E-mail: pericles.bosquetti@fatec.sp.gov.br

II Tecnóloga em Mecânica: processos de soldagem pela Faculdade de Tecnologia (FATEC) de Sertãozinho - São Paulo - Brasil. E-mail: nari_stz@hotmail.com

III Tecnóloga em Mecânica: processos de soldagem pela Faculdade de Tecnologia (FATEC) de Sertãozinho São Paulo - Brasil. E-mail: nanibadaro@ hotmail.com

IV Prof. Esp./Mestrando da Faculdade de Tecnologia (FATEC) de Sertãozinho - São Paulo - Brasil. E-mail: antonio.ventura@fatec.sp.gov.br

V Prof. Pós-Dr. da Faculdade de Tecnologia (FATEC) de Sertãozinho - São Paulo - Brasil. E-mail: diogenes.bosquetti@fatec.sp.gov.br
} 


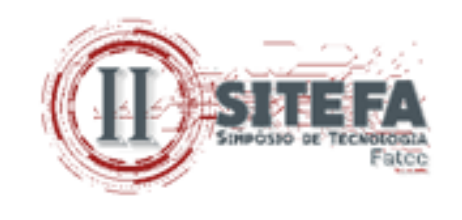

implementation of the booth could bring profits and how long it would be possible to recover the investments, explaining the savings generated.

Keywords: Costs. Reduction. Blasting. Industrial Paintings.

Data de submissão do artigo: 15/07/2019.

Data de aprovação do artigo: 19/09/2019.

DOI:

\section{INTRODUÇÃO}

Com a crise que o Brasil se encontra atualmente e com o mercado altamente competitivo, torna-se fundamental a redução de custos de um processo produtivo (WEG, 2019). Com o mercado altamente competitivo, as empresas necessitam cada vez mais aprimorar sua qualidade e planejar meios para diminuir perdas e evitar assim ficar de fora do mercado. Tendo em vista a importância e a necessidade de tratamentos de superfícies adequados para a proteção dos equipamentos para usos industriais e a crise da economia brasileira, observa-se que se procuram soluções de revestimentos que apresentem qualidade, durabilidade e baixo custo. Apesar de serem vistas como processos simples, as pinturas industriais, se adequadamente aplicadas, aumentam a vida útil dos equipamentos, evitando processos corrosivos por longos períodos. Além disso, exigem trabalhos de profissionais altamente treinados e qualificados, caso contrário resulta em grandes prejuízos (SHERWIN WILLIANS, 2019).

Pensando nisso, foi proposto à empresa "CEI" a instalação de cabines de jateamento e pintura, com intuito de reduzir custos excessivos na contratação deste serviço, para que favoreça a venda dos equipamentos fabricados, visto que a pintura faz parte do escopo de fornecimento desta empresa.

Destaca-se neste processo também a redução de custos logísticos com transportes intermediários, como o transporte das peças e das tintas, realizado por um terceiro. A redução dos custos também será favorecida muito pela redução do tempo de fabricação, visto que a cabine será somente de uso da CEI, onde a mesma controlará as prioridades de pintura. Com o planejamento acima proposto, serão diminuídas as não conformidades e obteve-se a melhoria do rendimento das tintas utilizadas.

\section{ENSAIOS DE CORROSÃO}

A finalidade de um ensaio de corrosão é testar a resistência de um metal à corrosão, fazer uma comparação entre diferentes metais e selecionar o mais resistente. É utilizado também para avaliar uma nova liga quanto à resistência à corrosão e a criar um método de proteção eficiente num meio agressivo, além de estudar a estrutura, a química e o mecanismo de corrosão. Há três métodos de ensaios de corrosão metálica: ensaio de laboratório, ensaio de campo e ensaio de serviço. O mais utilizado é o ensaio em laboratório, pois os resultados são obtidos em curto espaço de tempo e são confiáveis e reprodutíveis (RAMANATHAN, 1997).

Os fatores que favorecem os ensaios de laboratório são: corpo de prova reduzido, condições artificiais e controladas e o processo de corrosão que é acelerado, permitindo estudar mecanismos e avaliar o desempenho em vários meios em curto período. Assim, permite estudar, com eficiência, a influência de parâmetros, tais como: temperatura, tensão, umidade, composição do meio, composição do metal, microestrutura, condições superficiais, 


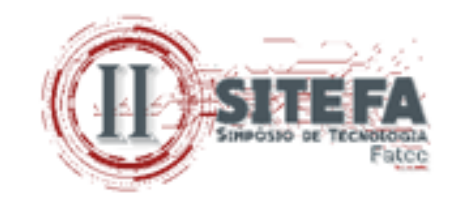

revestimentos entre outros. Alguns dos principais tipos de ensaios de corrosão em laboratório são: Ensaios de: Salt Spray (névoa salina), de imersão em meios diversos e de umidade saturada (EQUILAM, 2019). Nesse trabalho foram realizados ensaios de salt-spray .

Nos ensaios em campo, o corpo de prova normalmente utilizado é em tamanho real, as condições de corrosão são reais, sendo que as mudanças climáticas ocorrem de acordo com as estações do ano e como não são aceleradas, necessitam de longo tempo de ensaio, obtendo-se resultados mais reais, permitindo uma melhor avaliação de materiais e medidas de proteção (GNECCO; MARIANO; FERNANDES, 2016).

$\mathrm{O}$ ensaio de serviço requer muito tempo para que se tenham resultados, sendo que as amostras são colocadas na instalação ou estrutura real, sendo assim sai mais caro.

Os ensaios de corrosão têm a finalidade de caracterizar a agressividade de um determinado meio corrosivo e fornecer fundamentos básicos para fazer o controle da corrosão, e com esses resultados é possível obter a resistência de um material, capaz de suportar a corrosão causada pela ação de agentes químicos ou por oxidação (GENTIL, 2004).

\subsection{Ensaio de névoa salina}

O teste de nevoa salina (Salt Spray) é uma simulação dos efeitos de uma atmosfera marítima em diferentes metais com ou sem camadas protetoras. Basicamente, o procedimento de ensaio por névoa salina envolve a pulverização de uma solução salina sobre as amostras testadas, sendo feito em uma câmara com temperatura controlada e utiliza-se uma solução de $5 \%$ de sal (cloreto de sódio $-\mathrm{NaCl}$ ) que fica sendo constantemente pulverizada no interior da câmara a uma pressão de 0,8 a $1,2 \mathrm{Kgf} / \mathrm{cm} 2$. As amostras testadas são inseridas na câmara, e então, a solução salina é pulverizada como uma fina névoa sobre as amostras. A temperatura dentro da câmara é mantida constante à $35^{\circ} \mathrm{C}$, e a pulverização é contínua sobre as amostras que ficam constantemente úmidas e sujeitas à corrosão (EQUILAM, 2019).

O ensaio descrito é especificado pela ASTM B117 e os óxidos formados, que são produzidos na corrosão, são avaliados, e a duração do ensaio depende da expectativa da resistência à corrosão do revestimento, sendo que enquanto houver camada de proteção, haverá pulverização de névoa. A corrosão pode ter influência de fatores externos, sendo preciso muita cautela para avaliar a expectativa de vida de um revestimento. O ensaio de Salt Spray é muito popular, barato, padronizado, e bastante utilizado. A foto 1 apresenta uma câmara de ensaio de corrosão de névoa salina (Salt Spray).

Foto 1 - Câmara de ensaio de corrosão de névoa salina

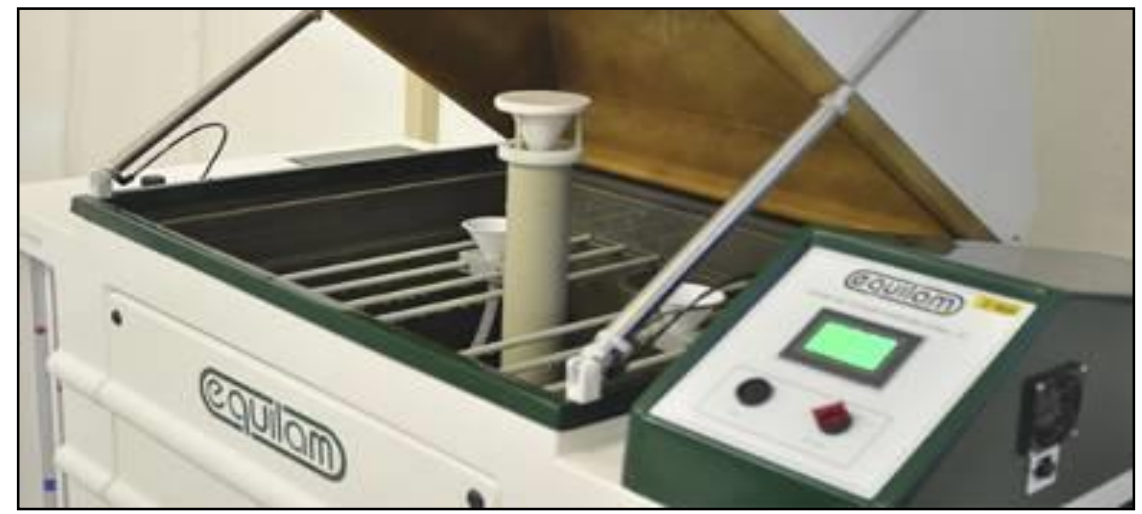

Fonte: os autores (2019) 


\section{PROCEDIMENTOS METODOLÓGICOS: jateamento e pintura}

Realizou-se uma visita na empresa prestadora de serviços de jateamento e pintura, e foram coletadas informações referentes aos procedimentos. Vários pontos foram observados, entre eles, os locais em que cada etapa do processo era realizada: os equipamentos utilizados, materiais consumíveis, entre outros, com o objetivo de entender os processos e saber os motivos que elevam os custos da proteção anticorrosiva das peças fabricadas pela CEI.

\subsection{Redução de custos em tintas: análise do processo de pintura e avaliação da eficácia por ensaio de salt spray}

É possível reduzir o custo de tintas diminuindo o seu consumo. O baixo consumo é obtido não somente quando se aplica uma camada de tinta fina, mas sim quando aplicada adequadamente por pessoal qualificado, sem que haja desperdícios, apresentando assim uma proteção anticorrosiva superior a de uma pintura com camada mais alta. Porém as normas de corrosão devem ser respeitadas, para que a camada não fique abaixo do especificado, apresentando defeitos como o overspray, não perdendo assim a eficácia da proteção e consequentemente não causando retrabalhos. Para determinar a eficácia, corpos de prova com camadas de tinta reduzidas, foram submetidos em ensaios de Salt Spray (névoa salina).

O teste foi realizado através da avaliação do aumento da largura de um corte feito em "X" na peça, e em seguida foi submetida na câmara de salt-spray, conforme norma NBR 8094 por 500h de exposição.

Para início do teste, foi realizada uma inspeção visual nos corpos de prova antes da pintura, onde constatou-se que dois corpos de prova possuíam grau de corrosão A, e dois corpos de prova possuíam grau de corrosão B. Para cada amostra, utilizou-se os componentes conforme a Tabela 1. As tintas utilizadas são equivalentes em sua aplicação, diferindo-se fundamentalmente na cor, para evitar confusão e mistura das amostras, pois foram produzidas pelos próprios operadores na linha de pintura.

Tabela 1 - Características dos corpos de prova preparados para os ensaios de corrosão (Salt-Spray)

\begin{tabular}{|c|c|c|c|c|c|c|c|}
\hline AMOSTRA & GRAU DE CORROSÃO & JATEAMENTO & ABRASIVO & PERFIL DE ANCORAGEM & PINTURA FUNDO & PINTURA ACABAMENTO & ESPESSURA FINAL \\
\hline CP1 & $A$ & $S A 21 / 2$ & S-280 & 40 a 60 micras & Sumaterm S200 & Sumatane HS BR & 111 micras \\
\hline $\mathrm{CP2}$ & $A$ & $S A 21 / 2$ & S-280 & 40 a 60 micras & Sumaterm S200 & Sumadur SP 530 & 93 micras \\
\hline CP3 & $B$ & $S A 21 / 2$ & malha 14 da Said Ltda. & 80 a 150 micras & Adlux 519 & Sumaterm 240 & 97 micras \\
\hline $\mathrm{CP4}$ & $B$ & $S A 21 / 2$ & malha 14 da Said Ltda. & 80 a 150 micras & Adlux 519 & Sumaterm 240 & 94,6 micras \\
\hline
\end{tabular}

Fonte: os autores (2019)

Submeteu-se os corpos de prova em uma câmara Salt Spray (névoa salina), cujos testes foram realizados sob condições das normas NBR 8094 e ASTM B117, que estabelecem procedimentos para o teste ser efetuado corretamente, como pressão, temperatura, e inspeções visuais a cada 24 horas. Ao término, é necessário verificar a ocorrência de "blistering" (empolamento) e penetração por corrosão e registrar as alterações em relação ao estado original. 


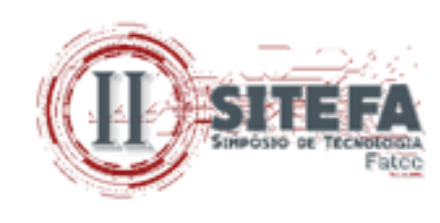

\section{RESULTADOS E DISCUSSÃO}

Para este estudo, foi usado como exemplo um equipamento fabricado para uma empresa de tratamento de água e esgoto, como pode ser visto na Figura 2. Após a fabricação, a peça foi encaminhada à empresa prestadora de serviços de jateamento e pintura. Os dados para pintura foram enviados juntos com a quantidade de tinta previamente calculada e comprada.

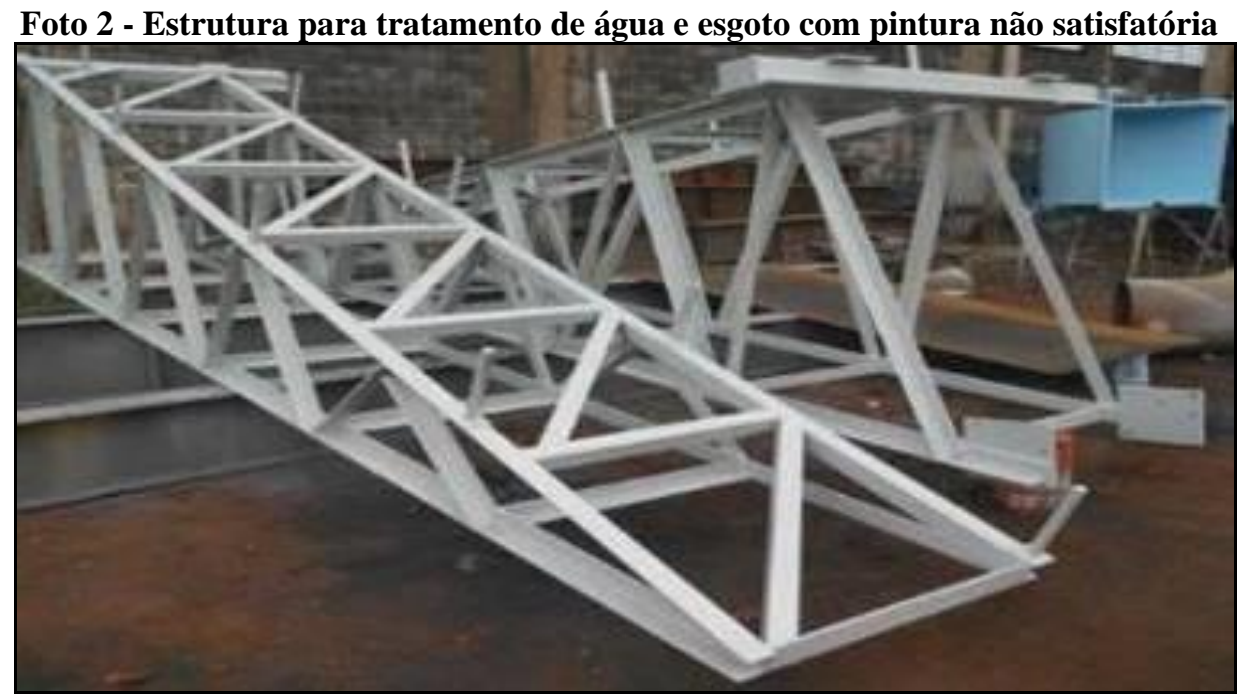

Fonte: os autores (2019)

No entanto, a peça retornou à CEI com espessuras mais baixas do que foi solicitado, o que levou a ser feito novamente o jateamento (para retirada da tinta), e a repintura da peça, além das tintas, que foram usadas o dobro do que foi considerado no orçamento.

Por esse motivo, e devido à grande quantidade de equipamentos apresentando espessuras de camadas de tinta muito finas, que foram observadas durante a visita, resolveu-se fazer um estudo mais aprofundado de causas e soluções aplicando-se o diagrama de Ishikawa, apresentado na Figura 1, procurando-se relacionar as causas com os efeitos. Desta forma, levantou-se as possíveis causas que geraram os resultados indesejados da pintura das peças em camadas inferiores e do alto consumo das tintas. Os aspectos levantados no diagrama, estão descritos em maiores detalhes nos subitens que seguem. 


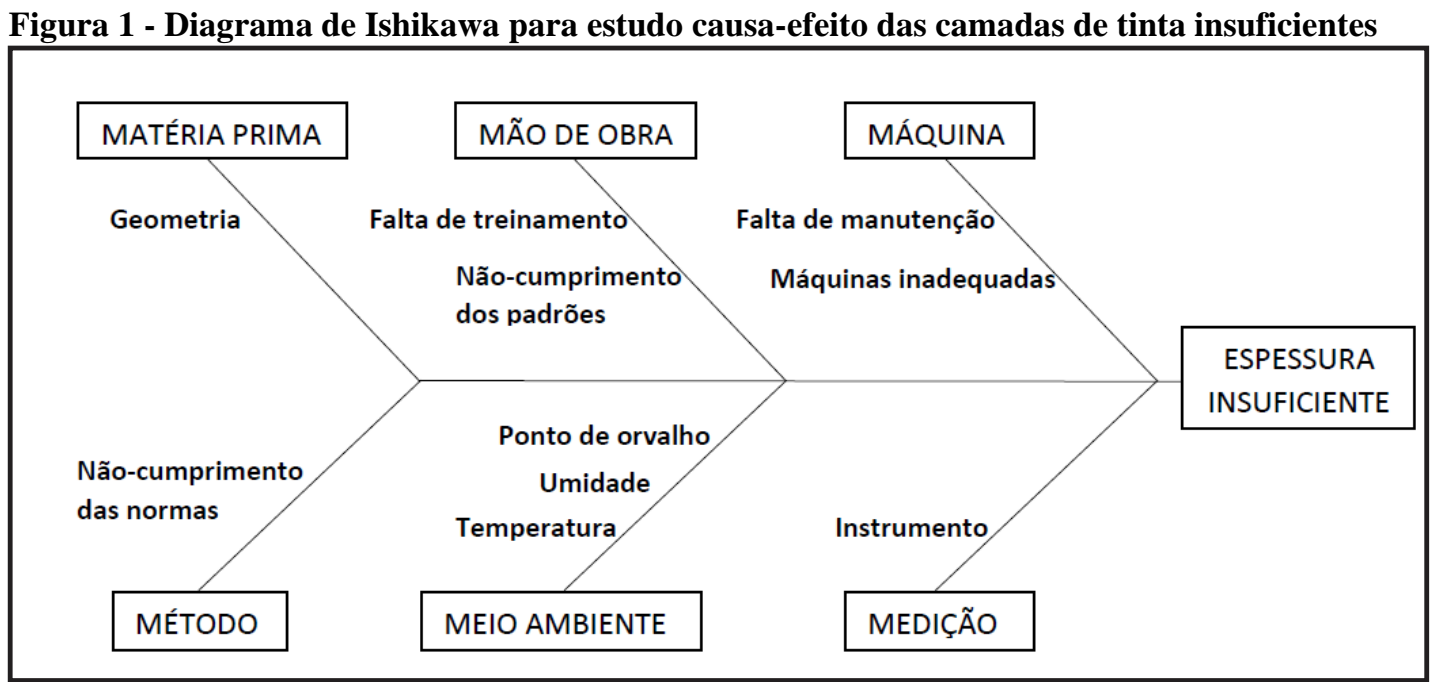

Fonte: elaborado pelos autores (2019)

\subsection{Matéria-prima e mão de obra}

O perfil de fabricação CEI abrange muitas áreas, sendo elas: açúcar e etanol, bens e capital, carcaças, energia, mineração, óleo e gás, siderurgia, sucroalcooleira, e ventiladores e dutos. Assim, a maior parte dos equipamentos que são fabricados pela CEI possuem perfil com muitas abas, cantos vivos, quinas e frestas, o que exige muita atenção e habilidade do jatista e do pintor $\mathrm{O}$ foco da maior parte das empresas de caldeiraria da região de Sertãozinho é a sucroalcooleira, e sendo assim, as empresas que prestam serviços de jateamento e pintura seguem o mesmo perfil, e assim nos leva a comparar o grau de dificuldade de pintar um Silo, que é utilizado em indústrias de açúcar e etanol, com a dificuldade muito superior de se pintar uma estrutura, que é utilizada para bens e capital, como mostram as Fotos 3 e 4.

Foto 3 - Aspecto de um Silo produzido pela empresa CEI

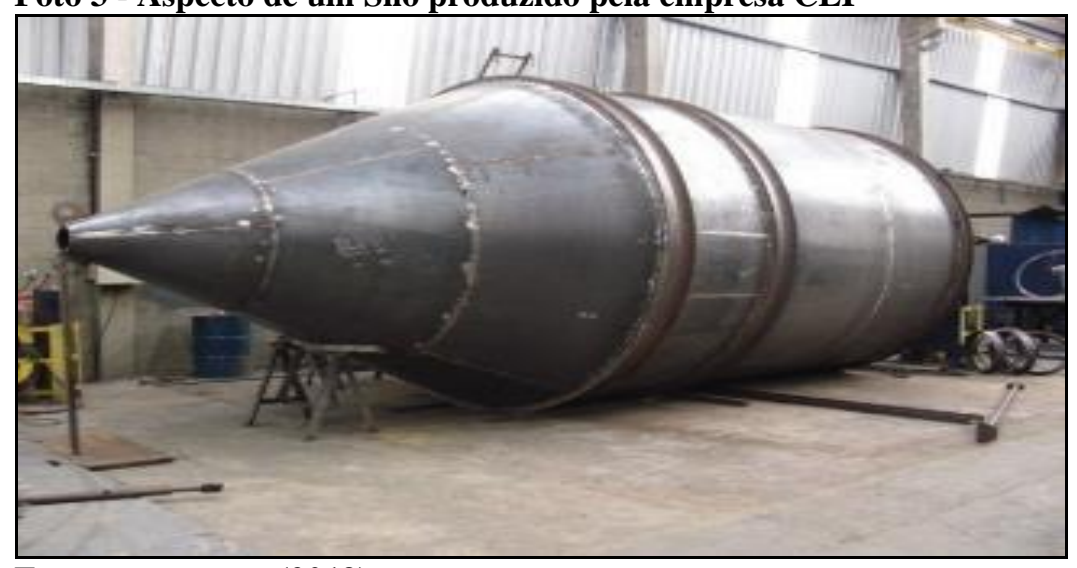

Fonte: os autores (2019) 
Foto 4 - Aspecto de Estrutura produzida pela empresa CEI

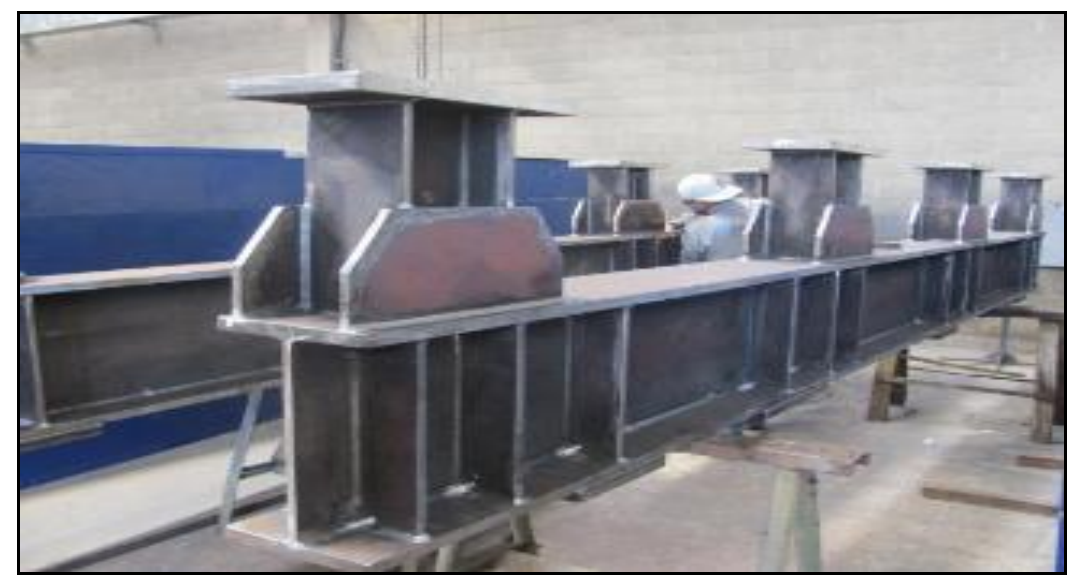

Fonte: os autores (2019)

Nota-se que o silo possui apenas alguns anéis em torno do seu diâmetro, que forma apenas algumas arestas na peça, e o restante é totalmente liso, sem muitos detalhes que possam dificultar a pintura e o jateamento. Já na estrutura, observa-se que há muitas arestas, e muitas áreas que são de difícil acesso, o que exige maior cuidado e habilidade do operador. $\mathrm{O}$ jatista, percebendo que não é possível jatear certas áreas, deve lixar estas áreas da peça. Os cordões de solda também precisam de atenção especial, fazendo o pintor pintar as arestas com pincel e depois aplicar a tinta com a pistola convencional nas demais áreas ao redor.

Comparando o silo, que é de perfil açúcar e etanol (perfil das empresas da região) e a estrutura (não comumente fabricado na região) sabe-se que o pintor pode ter o treinamento para a pintura de peças como o silo, e não ter para perfis como a estrutura estudada, pois pode não ser de interesse a especialização da pintura uma peça que raramente irá ser fabricada na região.

\subsection{Método e meio ambiente}

Alguns fatores observados podem levar a concluir que o local de pintura também não está apropriado para as peças da empresa CEI. O local onde é realizado o jateamento, não possui sistemas de exaustão e assim não cria um ambiente correto de trabalho, que é livre de poeiras, que podem prejudicar a pintura posterior. A cabine de pintura utilizada é aberta e, dependendo das condições climáticas, não é possível realizar a pintura, além de favorecer os desperdícios devido às correntes de ar, gerando atrasos na entrega do equipamento ou até mesmo causando a repintura das peças envolvendo maiores custos. Os ventos levam sujeiras até a peça pintada, deixando-a com a película não uniforme, e prejudicando a durabilidade, além do aumento do risco de ocorrer o efeito overspray (nuvem esbranquiçada de tinta), sendo necessário o retrabalho. As condições de trabalho dos operadores bem como os fatores ambientais também devem ser levadas em conta, uma vez que em um ambiente sem exaustor, ou sem sistema de filtragem do ar, são prejudiciais à saúde e ao meio ambiente, causando grandes impactos. 


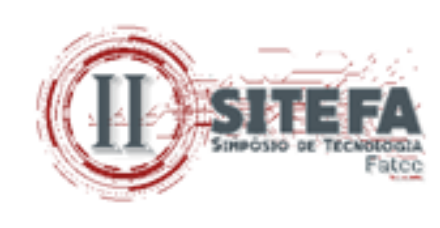

\subsection{Máquina e medição da camada de tinta}

A pistola usada no processo da CEI, foi a convencional, que trabalha com perdas de até $50 \%$ do que é realmente utilizado. Já o instrumento de medida da camada de tinta utilizada foi um medidor de camada, que é uma ferramenta muito conhecida pela sua praticidade, e muito utilizada, mas neste caso seu uso não foi eficiente. Não se pode afirmar que não foi utilizado nos testes, pois na visita, a empresa terceirizada afirmou o uso. Ele também pode estar desregulado ou descalibrado, e assim, não informou o resultado correto.

\subsection{Resultado da análise}

Todas as causas levantadas influenciam na ocorrência dos defeitos, mas as maiores influências nas espessuras insuficientes das camadas estão relacionadas à matéria-prima e à mão de obra. As outras causas levantadas influenciam diretamente elevando os custos e os prazos, visto que os equipamentos utilizados dobram a perda de tinta, e o prazo é em função do tempo. Por ser uma cabine aberta, só é possível realizar trabalhos com o clima favorável.

Sabe-se que a pintura dos componentes dos equipamentos fabricados, faz parte das negociações da CEI, e devido à essa condição, estima-se como mais viável, incorporar ao processo industrial de fabricação ambos os processos de jateamento e pintura. Desta forma, fez-se um estudo para uma adaptação do barracão já existente no pátio da CEI, utilizando-se local adequado com uso de exaustores dimensionados e área correta de armazenamento das tintas e das peças pintadas. Essa adaptação poderá dispensar o uso de transportes terceirizados, contando com o uso dos guinchos que a CEI já possui, e também dispensa gastos com aluguéis para armazenagens. Além destes, foram estudados e levantados os custos para outros itens de grande importância para essa adequação:

- Equipamentos para realização do jateamento e da pintura, que foram selecionados por custo x benefício, para não haver um grande custo inicial;

- Contratação de novos funcionários para tal serviço;

- Treinamento interno dos funcionários, que devido à CEI fazer parte da carteira de clientes da Sherwin Willians, poderá receber gratuitamente cursos de treinamento de pintura;

- Custo salarial, onde levantou-se que um funcionário especializado para pintura custa um pouco mais para a empresa, além dos custos trabalhistas como fundo de garantia (FGTS), Previdência Social (INSS), entre outros custos.

Para chegar a um estudo dos custos atingindo-se uma redução de custos com a internalização dos processos que envolvem a pintura, foram levantados os seguintes dados:

- Com os equipamentos para jateamento e pintura, a CEI terá um custo aproximado de $\mathrm{R} \$ 50.000,00$, o qual será divido para ser pago em um ano, resultando em $\mathrm{R} \$ 4.166,00$ por mês;

- Um jatista consegue jatear aproximadamente $1.500 \mathrm{~kg}$ de aço por dia, e um pintor consegue pintar aproximadamente $1.500 \mathrm{~kg}$ por dia. Sendo assim, para suprir a produção diária da CEI que é de $3.500 \mathrm{~kg}$ em média, serão necessários contratar dois jatistas, dois pintores, e de início, dois ajudantes. Desta forma, o custo mensal que a empresa terá com funcionários será de aproximadamente $\mathrm{R} \$ 14.932,34$;

- A CEI possui uma produção mensal de aproximadamente $80.000 \mathrm{~kg} \mathrm{em}$ equipamentos que necessitam de pintura, e que são aproximadamente $14 \mathrm{~kg}$ por hora trabalhada para cada um dos 35 funcionários da fábrica (considerando que são trabalhadas 7,33 horas por dia); 


\section{(10)}

- A aplicação de uma demão de tinta custa $\mathrm{R} \$ 0,20 / \mathrm{kg}$, e o jateamento mais utilizado, o SA $21 / 2$, custa $\mathrm{R} \$ 0,40 / \mathrm{kg}$.

Sabendo que o gasto mensal que a CEI terá é de aproximadamente $\mathrm{R} \$ 20.000,00$, e que sua produção mensal é de $80.000,0 \mathrm{~kg}$, o custo do jateamento e da pintura terá uma de redução de 70\%, comparado ao valor do custo para terceirização, como mostra a Tabela 2.

\subsection{Avaliação do desempenho de Corrosão através de baixas camadas de tinta}

As amostras CP1 e CP2 que foram jateadas com granalhas finas, resultaram em uma rugosidade de média a baixa, o que não promove uma boa ancoragem mecânica, facilitando o desplacamento da camada de tinta. Sabe-se que, nestas condições, é inviável a aplicação do método de camada baixa de tinta, pois para este perfil de jateamento já é recomendado o uso de camadas finas de tinta.

Para as amostras CP3 e CP4, será viável aplicar camadas baixas de tinta, pois como visto, os corpos de prova foram aprovados no teste, atendendo aos requisitos mínimos da penetração conforme norma, o que nos mostra que este método se torna uma opção para reduzir os custos. Neste caso, o material foi jateado com granalhas mais grossas, que produz uma rugosidade alta a média, e promove boa ancoragem mecânica e boa fixação da tinta, independendo da espessura da camada. A avaliação visual das amostras e as medidas da penetração à partir do corte em " $X$ " dos corpos de prova foram realizadas após 144 (parcial) e 500 horas de testes, e estão apresentados nas Fotos 5, 6, 7 e 8. Na Tabela 3, apresenta-se todos os resultados das medidas de penetração e desplaque da tinta após 144h e 500h de salt-spray.

Tabela 2 - Avaliação Comparativa de Custos realizando-se processo interno x terceirização

\begin{tabular}{c|c|c|c|c}
\hline Empresa & KG / Mês & $\begin{array}{c}\text { R\$ / Kg } \\
\text { (Jato SA 2 1/2 + duas demãos) }\end{array}$ & R\$ total / Mês & R\$ total / ano \\
\hline Terceirizada & $80.000,0$ & $\mathrm{R} \$ 0,80$ & $\mathrm{R} \$ 64.000,00$ & $\mathrm{R} \$ 768.000,00$ \\
\hline CEI & $80.000,0$ & $\mathrm{R} \$ 0,24$ & $\mathrm{R} \$ 19.166,67$ & $\mathrm{R} \$ 230.000,00$ \\
\hline
\end{tabular}

Fonte: os autores (2019)

Foto 5 - Penetração dos corpos de prova CP1 e CP2 após 144h Salt-Spray

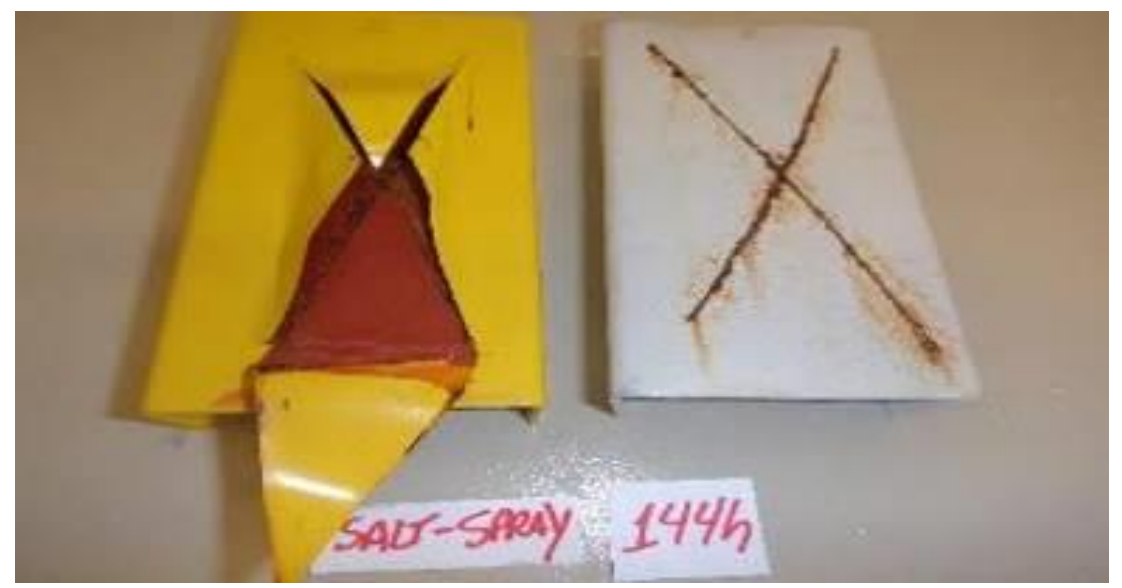

Fonte: os autores (2019) 


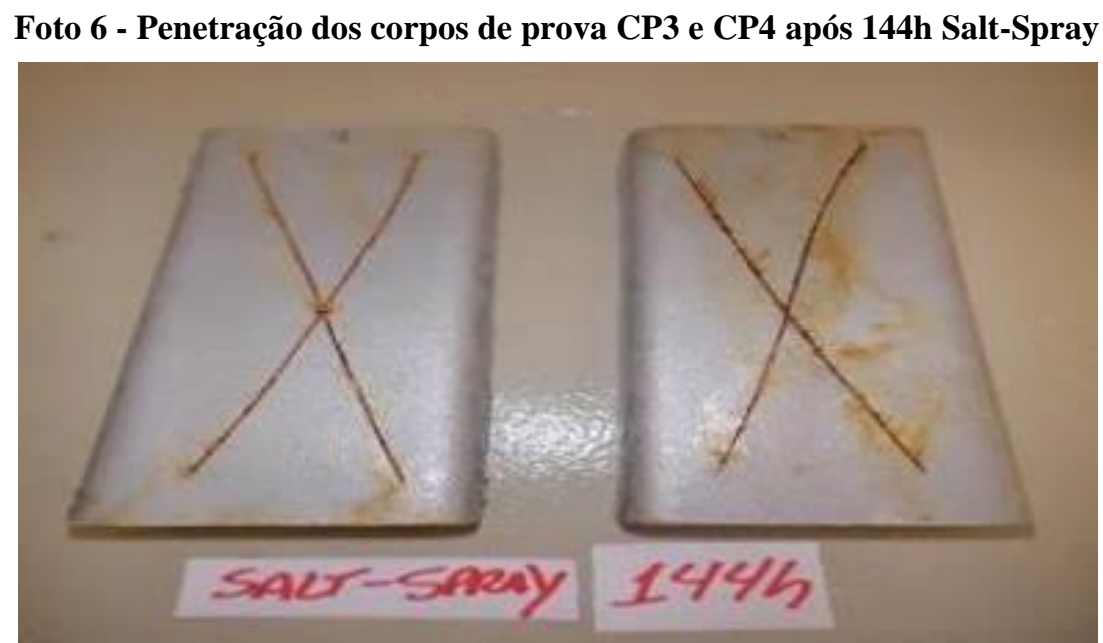

Fonte: os autores (2019)

Foto 7 - Penetração dos corpos de prova CP1 e CP2 após 500h Salt-Spray

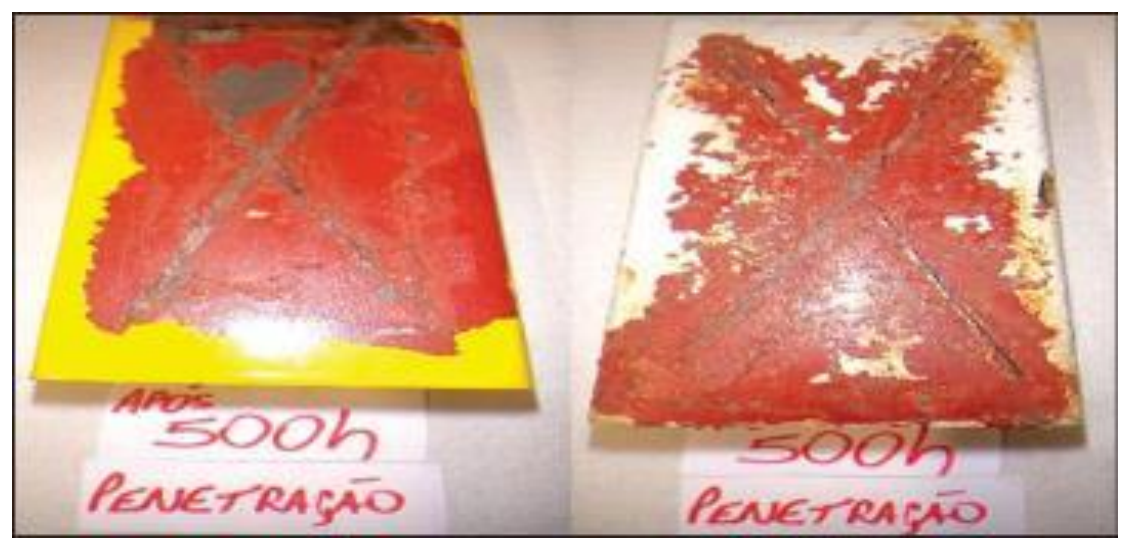

Fonte: os autores (2019)

Foto 8 - Penetração dos corpos de prova CP3 e CP4 após 500h Salt-Spray

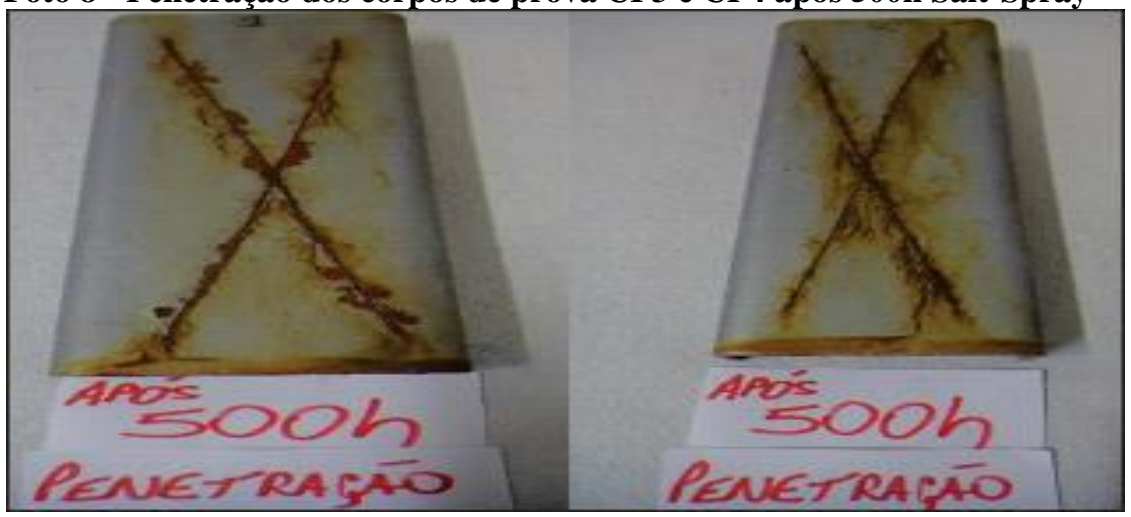

Fonte: os autores (2019) 


\section{(ii) SIIEEA}

Tabela 3 - Avaliação da Penetração pelo "X” após 144 e 500h de Ensaio de Salt-Spray

\begin{tabular}{c|c|c|c|c}
\hline CP & $\begin{array}{c}\text { Penetração Máx. } \\
\text { após 500h } \\
\text { (Especificado) }\end{array}$ & $\begin{array}{c}\text { Penetração } \\
\text { Após 144h Salt-Spray }\end{array}$ & $\begin{array}{c}\text { Penetração } \\
\text { Após 500h Salt-Spray }\end{array}$ & Situação \\
\hline CP1 & Máx 5mm & $\begin{array}{c}\text { Desplaque de mais de } \\
\text { 30mm }\end{array}$ & Desplaque total da tinta & Reprovado \\
\hline CP2 & Máx 5mm & Penetração de 3 a $5 \mathrm{~mm}$ & Desplaque total da tinta & Reprovado \\
\hline CP3 & Máx 5mm & 0,5 a $1 \mathrm{~mm}$ & 1 a $3 \mathrm{~mm}$ & Aprovado \\
\hline CP4 & Máx 5mm & 1 a $2 \mathrm{~mm}$ & 3 a $4 \mathrm{~mm}$ & Aprovado \\
\hline
\end{tabular}

Fonte: os autores (2019)

\section{CONCLUSÃO}

Após as análises das causas e avaliações dos ensaios de corrosão, pode-se considerar que a melhor opção no momento será a implantação de uma cabine de jateamento e pintura no pátio da CEI, já que esta empresa paga por mês, uma média de $\mathrm{R} \$ 64.000,00$ (considerando a pintura mais utilizada, o jateamento S A $2 \frac{1}{2} 2$ e duas demãos de pintura, independente da sua espessura) e na proposta, passará a pagar por mês aproximadamente $\mathrm{R} \$ 15.000,00 \mathrm{com}$ funcionários. Em um ano, esse custo diminuirá em média, 76,6\%. Com os equipamentos para jateamento e pintura, a CEI terá um custo de aproximadamente $\mathrm{R} \$ 50.000,00$. Dividindo esse valor a ser pago em um ano, será pago $\mathrm{R} \$ 4.166,00$ por mês. O custo será reduzido, então, para aproximadamente $70 \%$, sem considerar os impostos que a empresa paga.

Os custos com a adaptação do barracão com os equipamentos serão os mínimos, podendo ser recuperados em alguns meses, que deverão reduzir os custos pela diminuição das perdas e através do melhor controle das condições do processo.

As granalhas de aço podem ser reutilizadas até 350 vezes. Por esse motivo, não foi considerado seu custo, assim como de EPI's que já fazem parte dos gastos da CEI.

Com o teste salt-spray nos corpos de prova, sabe-se então, que as camadas de tintas podem ser reduzidas, sem que perca as propriedades de proteção anticorrosiva, em peças que seu perfil de ancoragem após o jateamento possua uma rugosidade alta a média.

\section{REFERÊNCIAS}

ASSOCIAÇÃO BRASILEIRA DE NORMAS TÉCNICAS (ABNT). NBR 8094: Material metálico revestido e não revestido - Corrosão por exposição à névoa salina - Método de ensaio. Rio de Janeiro: ABNT, 2017.

\section{ASTM B117. Standard Practice for Operating Salt Spray (Fog) Apparatus. 2018.}

EQUILAM. Equipamentos de ensaios Equilam. 2016.Disponível em:

http://www.equilam.com/produtos.php?id=240. Acesso em: 26 junho 2019.

GENTIL, V. Corrosão. 6.ed. Rio de Janeiro: Ed. LTC, Brasil, 2004.

GNECCO, C.; MARIANO, R.; FERNANDES, F. Tratamento de Superfície e Pintura. Rio de Janeiro: IBS/SBCA, 2016. 


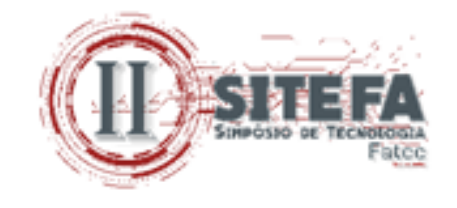

RAMANATHAN, L. V. Corrosão e seu Controle, 3. ed., Ed. HEMUS, Brasil, 1997

SHERWIN WILLIANS. Manual de preparação de Superfícies para Pintura. Disponível em: https://pt.scribd.com/doc/122643567/Preparacao-de-Surperficies-Sherwin-Williams.

Acesso em: 02 de jul. de 2019.

WEG. Desenvolvimento Tecnológico DT-12. Disponível em:

http://ecatalog.WEG.net/files/WEGnet/WEG-apostila-curso-dt-12-pintura-industrial-comtintas-liquidas-treinamento-portugues-br.pdf. Acesso em: 02 de jul. de 2019. 